\title{
1 Breeding status influences timing but not duration of moult in the Northern
}

2 Fulmar Fulmarus glacialis

3

4

5

ANTOINE GRISSOT, ${ }^{1,2^{*}}$ ISLA M. GRAHAM, ${ }^{2}$ LUCY QUINN, ${ }^{2}$

VEGARD S. BRÅTHEN, ${ }^{3}$ PAUL M. THOMPSON ${ }^{2}$

6

7

${ }^{l}$ ENSAT (Ecole Nationale Supérieure Agronomique de Toulouse), Avenue de l'Agrobiopole, BP 32607 - Auzeville-Tolosane, 31326, Castanet-Tolosan Cedex, France

${ }^{2}$ Institute of Biological and Environmental Sciences, University of Aberdeen, Lighthouse Field Station, 10 Cromarty IV11 8YJ, UK 
Seabirds are key marine top predator species that are often used as indicators of the environmental quality of the oceans. Their breeding phenology has been studied extensively, but their pelagic habits mean less is known about the phenology of other events during the non-breeding period. Here, we used miniaturised saltwater immersion light-based geolocators (GLS) to investigate moult phenology in individuals with known breeding histories in a population of Northern Fulmar Fulmarus glacialis in Orkney, Scotland. As seabirds spend more time on the water during moult, moulting periods can be identified from patterns of variation in the amount of time that birds are in contact with saltwater. Estimates of daily variation in this behaviour during the non-breeding period were based upon wet/dry sensors and then modelled to characterise the timing of the moult. Light-based geolocation provided information on the areas used by each individual during its moult period. Inter-individual variability in moult timing was investigated in relation to sex and breeding success in the previous summer. We found a sex difference in the location of the moult, but not in its timing. However, the timing of moult did differ between individuals that had succeeded or failed in their previous breeding attempt, with successful breeders moulting the latest. In contrast, the duration of moult did not depend on prior reproductive success, but there was evidence of inter-annual variation in moult duration. GLS studies have provided a step change in our understanding of the at-sea distribution of pelagic seabirds. Our work highlights how activity data from these devices can add value to such studies by identifying key phases of the annual cycle, and locations at these times, when seabirds may be at particular risk. Furthermore, our findings indicate that individual and inter-annual variation in breeding success may influence phenological patterns in other phases of their annual cycle.

Keywords: phenology, moulting, non-breeding, Procellariiformes, light-based geolocation 
Avian moult is an energetically demanding process (Cherel et al. 1994, Murphy 1996) which can also incur indirect costs by impairing flight (Swaddle \& Witter 1997, Guillemette et al. 2007, Gutowsky et al. 2014). Temporary periods of flightlessness, or lower flight performance, increase vulnerability to predators and can limit access to resources (Green et al. 2004, Guillemette et al. 2007). Together, these direct and indirect costs of moult can result in trade-offs between the timing of moult and the two other major avian life-history events: breeding and migration (Bridge 2011). Most work on these trade-offs has focused on passerines, which moult after breeding and prior to migration; thus allowing the moult process to be observed directly (Hemborg \& Lundberg 1998). There have been extensive studies of breeding phenology in many seabirds (e.g. Keogan et al. 2018). However, moult generally takes place once birds have dispersed from breeding grounds, constraining direct observations of pelagic seabirds. Information on the timing of their moult has therefore been dependent upon ad hoc observations at sea or analyses of carcasses (e.g. Brown 1988, Edwards \& Rohwer 2005, Bugoni et al. 2015). As a consequence, there is limited information on the timing of moult in many pelagic seabirds (Bridge 2006, Gutowsky et al. 2014, Cherel et al. 2016) and the key areas that these birds may be using at this time (e.g. Harris et al. 2014). Given that reduced flight performance may increase their vulnerability to various natural and anthropogenic stressors (Green et al. 2004), better information on moult patterns is also required to support effort to manage high seas areas to protect pelagic seabirds.

In the past, moulting strategies amongst Procellariiformes have been particularly difficult to characterize. Some studies have suggested that moult and reproduction are more likely to overlap in this order (Bridge 2006). However, this can be difficult to assess unless studies of moult are conducted on birds of known reproductive status (Allard et al. 2008). Recent development of geolocation loggers has allowed investigation of the non-breeding period of seabirds at unprecedented temporal and spatial scales (Croxall et al. 2005). Most commonly, geolocation loggers have been used to describe migratory pathways and wintering grounds (e.g. Frederiksen et al. 2012, Dias et al. 2013, Fayet et al. 2017). However, most geolocation devices also have salt water immersion sensors that can be used to test whether moulting seabirds have quasi-flightless periods where most time is spent on the water (Mackley et al. 2011, Gutowsky et al. 2014, Cherel et al. 2016). Gutowsky et al. (2014) pioneered the use of wet-dry logger data to identify the moult period in North Pacific albatrosses, and obtained a clear signal that underpinned the 'quasi-flightless stage hypothesis'. Cherel et al. (2016) subsequently verified this by demonstrating that immersion data could be used to characterize the timing and location of moult in three smaller subantarctic petrel species. They firstly characterized moult in the Blue Petrel Halobaena 
caerulea, a reference species that is known to renew its plumage in autumn, and identified a strong peak in daily time spent sitting on water during the expected moult period. They then used this peak as a proxy to characterize the contrasting moult strategies of two other petrel species. This approach now opens up new opportunities for understanding moult strategies in a range of pelagic species by integrating biologging data with individual based demographic studies; thereby permitting assessments of variation in the timing of moult in relation to known reproductive performance.

In this study, we used data available from geolocation loggers with wet/dry sensors to characterize the timing and location of moult in a well-studied colony of Northern Fulmars Fulmarus glacialis in Scotland. Existing information on moult patterns in this species has been based either upon observations of birds around breeding colonies (Carrick \& Dunnet 1954, Allard et al. 2008) or analysis of beached or by-caught individuals (Quinn et al. 2016). These techniques have shown that the moult occurs post-breeding, but they cannot be used to explore variation in moult duration or links between moult timing and reproductive success. Here, our primary objectives were to explore whether the timing or duration of moult varied between birds that bred unsuccessfully or successfully in the preceding breeding season, and birds of different sex. In addition, we aimed to identify the areas used by Northern Fulmars from this population during their moult, to assess whether there are discrete areas where they may be more vulnerable to anthropogenic stressors.

\section{METHODS}

\section{Study site and logger deployment}

Fieldwork was conducted on Eynhallow, Orkney $\left(59^{\circ} 8^{\prime} \mathrm{N} ; 3^{\circ} 8^{\prime} \mathrm{W}\right)$ where individual based studies of breeding Northern Fulmars have been ongoing since the 1950s (Dunnet 1991). Individuals have been marked using unique colour ring combinations, and information on their reproductive status has subsequently been based upon observations made during three standardized visits to the colony in each breeding season; during the incubation, hatching and fledging periods (for details see Lewis et al. 2009, Cordes et al. 2015).

Since 2006, these studies have been developed to include assessments of the foraging distribution of known breeders (Edwards et al. 2016, Quinn et al. 2016). These have been based upon the deployment of miniature Global Location Sensing (GLS) loggers on adult breeders at the colony. Several different GLS models were used during the study, primarily MK 3 and MK 5 loggers produced by British Antarctic Survey (Cambridge, CB3 OET, UK), 
MK3006 loggers produced by Biotrack (Wareham BH20 4PL, UK) and C250 loggers

110 produced by Migrate Technology Ltd. (Cambridge, CB1 0QY, UK). Loggers weighed

111 between $1 \mathrm{~g}$ and $2.5 \mathrm{~g}$, and were fixed to one of the darvic leg rings using cable ties, giving a maximum total device weight of $4 \mathrm{~g}(<0.5 \%$ of the lightest individual's body weight).

Devices were recovered 1-3 years later, generally at the nest but occasionally after

114 birds were captured in flight. Annual attendance of breeding adults at this colony varied

115 considerably, and can be as low as 50\% in some years (Thompson \& Ollason 2001). This, in

116 turn, affected the likelihood of recovering loggers, resulting in an average recovery rate of

$11746 \%$ over one year to $76 \%$ after two or more years.

118 All devices recorded light level and saltwater immersion every 3 seconds, and stored

119 the maximum light levels and the number of wet samples in every 5- or 10-minute period.

120 After recovery, data were downloaded and extracted using either the BASTrak software

121 (British Antarctic Survey) or IntigeoIF (Migrate Technology Ltd.)

\section{Moult characterisation and individual variability in the timing of moult}

124 The key purpose of this study was to investigate the individual timing and location of the

125 moult in relation to the previous breeding attempt. Northern Fulmars at this colony typically

126 lay their eggs during the last two weeks of May, and the first annual colony census of

127 incubating birds occurs as close as possible to the $1^{\text {st }}$ of June (Dunnet 1991). We therefore

128 defined the annual cycle as the period between June $1^{\text {st }}$ of one year and May $31^{\text {st }}$ of the

129 following year.

130 Due to occasional logger failure or limited memory capacity on multi-year

131 deployments, activity data were not always available throughout complete deployments.

132 Previous studies of carcasses indicate that moult in Northern Fulmars occurs after the end of

133 the breeding season and is completed by the end of December (Carrick \& Dunnet 1954,

134 Allard et al. 2008, Quinn et al. 2016) when birds start to attend the colony periodically until

135 the next breeding season (Coulson \& Horobin 1972, Macdonald 1980, Slater 1990). For these

136 analyses, we therefore selected only those birds and years in which activity data were

137 available throughout the entire mid-August to mid-December period. Furthermore, we only

138 used data from years in which there were activity records from at least 10 birds, and birds for

139 which sex and breeding status in the previous breeding season were known. This resulted in a

140 dataset that included 139 moult cycles (82 individuals; 44 males and 38 females; see

141 Supporting Information Table S2 for detailed sample sizes per season).

142 Following Cherel et al. (2016), we used daily variation in the proportion of time spent

143 sitting on the water to define the moult period at both population and individual levels. 
144 Immersion data from the different logger models were used to first classify each bird's

145 activity within the 5- or 10-minute sample periods (depending upon the logger model used).

146 Given that the logger is placed on a leg ring and is fully submerged when birds spend their

147 time sitting on the water, we used the daily accumulated time that the logger had been fully

148 submerged in saltwater (i.e. total time spent fully submerged in a 24 hour period; midnight

149 UTM to midnight UTM) as a proxy for this behaviour. Sampling periods where the logger

150 was only partly submerged (i.e. a mix of wet and dry records on a sample period) or fully dry

151 were therefore used to characterise other behaviours (e.g. foraging and in flight or on land,

152 respectively) and excluded from this data analyses. Purpose written R script was used to

153 obtain the daily proportion of time in which each bird was sitting on the water throughout

154 each deployment (available in Supporting Information Appendix S1).

155 To characterise variation at the population level, we calculated a mean value for the

156 proportion of the day which birds spent on the water throughout the annual cycle. Individual-

157 based estimates of the timing of moult were then based upon a Generalized Additive Model

158 (GAM) that was fitted to the 'wet' data for each bird's annual cycle using the approach

159 developed by Cherel et al (2016). Following Cherel et al. (2016), the core moult period was

160 defined as the time window (consecutive days) when the predicted 'wet' variable exceeded

$16175 \%$ of the value of the peak in the daily proportion of time wet (see Supporting Information

162 Fig. S1 for an example GAM). These GAM results also provided estimates of the date of the

163 peak of wetness, and start, median, end dates, and duration of the moult for each individual.

$16495 \% \mathrm{CI}$ around the fitted GAM were used to provide an estimate of variability around each

165 individual estimate of moult duration.

167 Influence of breeding status on the timing of moult

168 Data on an individual's moult phenology were then integrated with data from colony

169 observations to explore how moult characteristics were influenced by an individual's previous

170 breeding success. Variability in moult characteristics were investigated using a linear mixed

171 model fitted with maximum likelihood in the lme4 package (Bates et al. 2015). The bird's ID

172 was incorporated in the model as a random effect to prevent pseudo-replication due to the

173 presence of data from several different annual cycles for some birds. We used start date,

174 median date and duration of the moult as response variables. The end date of the moult was

175 highly correlated to start date and duration, so was not included as a response variable. We

176 included the following explanatory variables: sex of the individual, year and previous

177 breeding success. Visits were made to the study colony on three occasions in each breeding

178 season: in late May to identify which birds were on eggs; in mid July to estimate hatching 
success; and in mid August to record the presence of chicks prior to fledging (see Lewis et al. 2009). Breeding success was therefore classified into four categories: 1) Not recorded breeding at the colony in that year, 2) Failed on an egg, 3) Failed on a chick, 4) Successfully fledged a chick. An interaction between sex and reproductive success was also incorporated in the model to explore whether males and females responded in the same way to a successful or failed reproductive attempt. The significance of each explanatory variable was tested with the 'Anova' function using type III Wald Chi-square tests from the car package (Fox \& Weisberg 2011). Model selection was carried out by removing every non-significant factor, and confirming the better fit of the model using Akaike Information Criterion, correcting for small sample size, with the function 'AICc' from the MuMIn package (Barton 2016). Models with $\Delta \mathrm{AICc} \leq 2$ were considered the best of the set of candidate models. Following this analysis, multiple comparison post-hoc Tukey tests were performed to assess specific differences within significant variables, using the 'glht' function from the multcomp package (Bretz \& Westfall 2008). Assumptions of homoscedasticity and normal distribution of the model's residuals were verified for every candidate model.

All analyses were carried out with R version 3.1.3 (R Core Team 2015) and statistical significance was taken to be $P<0.05$.

\section{Spatial distribution of individuals during their quasi-flightless moult period}

198 Geolocation data were then used to characterise the distribution of individual fulmars during their core moult period. Twilight events where determined from where light curves intersected with a selected threshold of 9 for MK 3, 5 and 3006 geolocators and 11 for C250 geolocators, using the BASTrack (British Antarctic Survey; Fox 2010) or IntiProc software from Migrate Technology Ltd (Coton, Cambridge, UK; Fox, 2015), respectively. Twilight events were checked visually to remove data from days with constant light or dark, or where shading events occurred. If a light curve clearly suggested a more correct placement of a sun event, events were moved. On average, $6 \%$ of resulting twilight events were moved.

The light data were further processed following procedures in Hanssen et al. (2016). Sun elevation angles were determined individually for each geolocator (ranging from $-1^{\circ}$ to $4.5^{\circ}$ ) by combining in-habitat calibrations, using the breeding colony as a reference point, with visually inspecting latitude vs. date plots (Hanssen et al. 2016, Supporting Information

210 Fig. S2). A smoothing process was applied twice to positional data to reduce location errors 211 (Hanssen et al. 2016, but see Phillips et al. 2004 and Fox, 2015). Following this procedure,

$21275 \%$ individuals had daily locations for $>95 \%$ of their moult period (Supporting Information 213 Table S1). In those few $(<5 \%)$ cases where daily locations were available for $<70 \%$ of days 
214 during the moult cycle, this was typically because birds were using high Arctic areas at this 215 time of year.

Information on the start and end date for each individual's moult (as defined by the GAM) was used to filter the resulting geolocation data and estimate the great circle distance between each of the bird's twice-daily locations and the breeding colony. To visualise differences between individuals, we estimated the geographic mid-point of locations obtained for each bird during their respective moult periods, excluding locations during the equinox, using the function 'geomean' in the geosphere package (Hijmans 2016). We used the distribution of distances to the colony to provide an estimate of variability and comparison of male and female locations during the moult period. For many individuals, the moult period included part of the autumn equinox ( $8^{\text {th }}$ September $-20^{\text {th }}$ October). To explore whether this biased estimates of the geographic mid-point, we also calculated a second geographic midpoint for each bird that included data from the equinox by using observed values of longitude and proxy values for latitude that were based upon that individual's moult locations from outwith the equinox.

The distance between the geographic mid-point of male and female moult locations and the breeding colony was also compared using linear mixed models fitted with maximum likelihood in the lme4 package (Bates et al.2015), with bird ID as a random effect and sex of the bird as the explanatory variable. Significance of the explanatory variable was tested with the 'Anova' function as above.

\section{RESULTS}

\section{Moult characterisation and individual variability in the timing of moult}

At the population level, there was a clear increase in the daily proportion of time spent on the water in the period between July and December (Fig. 1). The same pattern was observed by plotting the raw data for each of the 139 annual cycles, and individual patterns were successfully quantified by plotting a GAM for each cycle. Overall, the earliest moult start date was July $6^{\text {th }}$, and the latest end date was December $23^{\text {rd }}$. However, there was marked variability in the timing of the moult within this time-window (Fig. 2). For the start date of moult, the median was $18^{\text {th }}$ of August (interquartile range: $7^{\text {th }}-29^{\text {th }}$ August). The median date of the moult was $21^{\text {st }}$ September (interquartile range: $8^{\text {th }}-30^{\text {th }}$ September), whilst the median end date for the moult was $23^{\text {rd }}$ October (interquartile range: $13^{\text {th }}$ October $-4^{\text {th }}$ November). 
The median duration of the moult was 68 days (interquartile range: 57 -78 days; Supporting Information Table S1 provides the detail of these estimates for each individual bird).

Influence of life-history traits and annual variation on individual variability

Inter individual variability in the timing of the moult was explained by different explanatory variables for each of the three moult characteristics we chose to model (i.e. start date, median date and duration; see Table 1). For start date, the best model contained only the previous breeding status as an explanatory variable (Table 2). Birds of differing breeding status exhibited significant differences in the start date of their subsequent moult $\left(\mathrm{LMM}, \chi^{2}=\right.$ 248.50, $P<0.001$; Fig. 3). Non-breeders and birds that failed on an egg started their next moult at a similar time (Tukey, $P>0.05, z=0.5$ ): $26^{\text {th }}$ July \pm 2.8 days (mean \pm SE) for nonbreeders and $27^{\text {th }}$ July \pm 2.3 days for birds who failed on an egg. Birds that failed on a chick started their moult significantly later than both other groups, around the $13^{\text {th }}$ August \pm 2.3 days (Tukey, $P<0.05, z=5.6$ and 5.8, respectively). Finally, successful breeders moulted latest (Tukey, $P<0.05, z=11.3,12.4$ and 7.4 compared to non-breeders, and birds that failed on an egg or a chick groups, respectively). On average, these successful birds started their moult on $27^{\text {th }}$ August \pm 0.9 days, one month after birds which failed on eggs or were not recorded breeding (Fig. 3). There were slight annual differences in the start of moult, but these were not significant (see Table 3).

Differences in the median date of the moult were less clear (Table 2). There was slightly more support for the model containing both sex and breeding status than the model containing only breeding status $(\triangle \mathrm{AICc}=1.4)$. However, the difference in median date between the sexes was slight $\left(\mathrm{LMM}, \chi^{2}=3.67, P=0.055\right.$; Males: $21^{\text {st }}$ September \pm 1.8 days; Females: $18^{\text {th }}$ September \pm 1.9 days). On the other hand, the difference in median date of moult for individuals of differing breeding status was highly significant (LMM, $\chi^{2}=204.53, P$ $<0.001)$ and showed a similar pattern to that seen in start dates. Non-breeders and birds that failed on an egg had similar median dates $\left(2^{\text {nd }}\right.$ September \pm 2.1 and $1^{\text {st }}$ September \pm 2.2 days; Tukey, $P>0.05, z=-0.228)$, median date for birds that failed on a chick was later $\left(16^{\text {th }}\right.$ September \pm 2.1 days, Tukey, $P<0.05, z=4.33$, and 5.24, respectively) and that for successful birds was latest $\left(30^{\text {th }}\right.$ September \pm 1.1 days, Tukey, $P<0.05, z=9.73,11.63$ and 7.08, respectively). Similarly, there was a slight but not significant annual difference in median date of the moult.

AICc differences were even smaller for models using duration as a response variable (see Table 2). Based on the same process, we selected the model with the smallest AICc, which contained only the cycle year as an explanatory variable. Annual variation was 
significant (LMM, $\chi^{2}=17.806, P=0.003$ ), with durations in 2008/09 being up to 2 weeks

284 longer than in 2009/10 and 2010/11, and with intermediate values for the remaining years

285 (Table 3).

286

\section{Location during the moult}

288 Combining the activity data with geolocation data, we found that moulting Northern Fulmars 289 from the Eynhallow colony were located across a broad geographical range from the mid290 Atlantic to the Barents Sea (Fig. 4). One cluster of individuals was found over the North Sea 291 and continental shelf. Smaller clusters of moulting individuals occurred in the mid-Atlantic 292 and along the Norwegian Shelf and into Arctic waters of the Barents Sea. A similar pattern was observed when using additional longitudinal information from the equinox, suggesting that there was no east-west bias as a result of excluding all locations from the equinox (Supporting Information Fig. S2). Females tended to predominate in areas further from the colony (i.e. mid-Atlantic and Arctic locations) and males were more common over the North Sea. This sex difference in the distance between the geographic mid-point of moulting locations and breeding colony was highly significant (LMM, $\chi^{2}=23.03, P<0.001$; Fig. 5).

\section{DISCUSSION}

This study suggests that the method developed by Cherel et al. (2016) to characterise the timing of the moult in small petrels can be extended to other Procellariiformes. In applying this method, we assume that observed changes in the proportion of time that birds spent wet result from a change in flight performance, as originally suggested by Gutowsky et al. (2014). In previous studies using wet-dry sensors on Procellariiformes, foraging activity has typically been characterised by 5- or 10-minute periods containing a mixture of both wet and dry samples (Mattern et al. 2015). An increase in sample periods in which birds remain on the water could potentially represent an alternative surface foraging behaviour. However, whilst proxies of diet indicate that foraging characteristics of Northern Fulmars can change between late winter and the breeding season (Owen et al. 2013), the marked increase in daily time spent on the water occurred much earlier in the non-breeding period (Fig. 1). This change in wet-dry activity also coincides with previous estimates of the timing of primary moult based upon analyses of dead fulmars (Quinn et al. 2016). We therefore suggest that the activity data 
316 from this population indicate that all individuals had started their moult in July or August, and 317 had finished moulting by late December.

The use of activity data from known individuals provided additional information on moult phenology that offers new insights for broader comparative studies (Bridge 2011). First, variations in the amount of time that birds spent on the water provided estimates of the duration of an individual's moult, which was typically around two months (Fig. 2). Existing estimates of moult duration in seabirds are based on approximate dates for moult initiation and completion, potentially leading to overestimation of an individual's moult pattern (Bridge 2006). Activity based techniques can therefore provide finer-scale individual level measures which can be used to compare the duration of moult both between and within species. Second, by combining these data with information on known reproductive histories, we were able to explore the relationship between the timing of breeding and moult at the individual level. Individual-based studies linking variation in moult patterns to reproductive success are rare amongst seabirds, and were previously based only upon moult characteristics obtained from observations of known breeders at the colony (Barbraud \& Chastel 1998, Rohwer et al. 2011). Detailed colony-based studies can now use these techniques to explore interactions between key life-history events both at the colony (breeding success) and at sea (migration schedules (e.g. Catry et al. 2013) and moult patterns).

Our analyses revealed that inter-individual variability in the timing of the moult was related to success during the previous breeding attempt, with non-breeders or birds that failed early in the season starting their moult around one month earlier than successful breeders (Fig. 3). These data are in accordance with a recent experimental study on Cory's Shearwater Colonectris borealis, which used a combination of tracking and stable-isotope analysis to demonstrate that birds that were induced to fail moulted earlier compared to successful breeders (Ramos et al. 2018). Colony observations of albatrosses have also shown that breeding success can influence subsequent moult in those larger species that have a complex biennial moult (Furness 1988, Prince et al. 1993, Rohwer et al. 2011). In those cases, failed breeders increased the number of primary flight feathers that they moulted, which could result from an earlier initiation and/or longer moult duration. Detailed mechanisms controlling prebasic moult remain unclear, but our observations are in line with the suggestion that higher levels of sex-steroid hormones delay the onset of moult in active breeders (Hahn et al. 1992). In passerines, delays in moult initiation typically require a faster moult to maintain migration schedules (Hahn et al. 1992). However, our data suggest that breeding success did not influence the duration of the moult, meaning that the pattern observed for the start date of moult (Fig. 3) was retained in the median and end dates of moult. Experiments on European 
Starlings Sturnus vulgaris demonstrated that shorter moult duration led to the production of lower quality feathers (Dawson et al. 2000), which could compromise future reproductive success in seabirds that make long foraging trips during chick rearing (Rohwer et al. 2011). In the absence of a fixed migration schedule, individual moult durations in Northern Fulmars may be less variable in order to maximise feather quality although, as discussed below, interannual variation in duration suggest moult duration may be affected by external environmental conditions.

These findings also provide new insights into previous studies that used traditional techniques to assess the extent to which moult and breeding overlap. Northern Fulmars that breed successfully are constrained to central place foraging from the colony until their chicks fledge in late August or September. Whilst non-breeders and early failures may leave the colony earlier, observations of marked birds indicate that not all do so (Anderson 1962, P. Thompson unpubl. data). This can result in an overlap between observations of breeding and moulting birds at the population level, but these results demonstrate that events do not necessarily overlap at the individual level. No evidence of active breeders moulting flight feathers was found at our study site (Carrick \& Dunnet 1954, this study) or at a Canadian Arctic colony (Allard et al. 2008). Allard et al. (2008) suggested that their observed temporal overlap of breeding and moulting individuals resulted from large scale movements and overlapping ranges of birds from different colonies, with moult occurring earlier in colonies characterised by earlier egg-laying. However, our results suggest that Allard et al.'s (2008) observations could simply result from within colony variation in reproductive success, as failed breeders that remain around the colony could initiate moult up to a month earlier than the active breeders. Nevertheless, we made only low intensity colony visits in the last few weeks of chick rearing, when very few adults were observed. Thus, some evidence of moult could have been missed.

Rohwer et al. (2011) highlight the potential for extending colony-based studies to explore trade-offs between moult and reproduction. Estimates of moult phenology from activity loggers provide additional opportunities to extend such studies by following birds after dispersal from the colony, thus exploring unresolved questions about timing and duration of seabird moult arising from analyses of carcasses (Bridge 2011). Atlantic Puffins Fratercula arctica for example have a protracted period of moult with bi-modal peaks in both October and March, suggesting they may moult twice during the non-breeding season (Harris et al. 2014). Individual based data are required to test such hypotheses, and explore how these patterns relate to previous reproductive histories. However, interpretation of individual bouts of at-sea behaviour in auks are more complicated because they may withdraw one leg into the 
plumage while sitting on the water (Linnebjerg et al. 2014). Nevertheless, modelling longerterm variations in behaviour using the approach developed by Cherel et al. (2016) may provide opportunities to use existing datasets (e.g. Fayet et al. 2017) to compare putative moult patterns in individuals of known reproductive status over multiple years and from different colonies.

As reported by Allard et al. (2008), we found no sex differences in the timing of moult. There was, however, a tendency for females to moult at more distant locations from the colony, in line with sex-differences in the foraging areas used by these birds during the winter (Quinn 2014) and pre-laying exodus (Edwards et al. 2016). GLS studies of nonbreeding distribution are already providing new insights into potential moulting areas (e.g. Harris et al. 2015). The use of activity data to refine estimates of birds' locations during critical moult periods can further support risk assessment and conservation planning (Croxall et al. 2012). Unlike many other waterbird species (Kirby 1995) Norther Fulmars from this single colony were dispersed over a wide geographical area rather than congregating at specific locations during their moult. Current conservation activity often focuses on identifying Important Bird Areas, where seabirds may aggregate to feed or engage in other key behaviours such as moulting (Lascelles et al. 2016, Krüger et al. 2017). Our data highlight that focused area-based conservation interventions may be less easily applied to highly dispersed and wide-ranging species such as Northern Fulmars. Observed levels of dispersion during the moult suggests that the viability of individual colonies should be buffered against localized impacts such as oil spills, which could adversely affect breeding populations aggregating in common wintering areas (Fauchald et al. 2002). At a finer-scale, however, it remains possible that birds from this single colony do still aggregate during the moult, potentially associating with individuals from a broad range of colonies around the North Atlantic. Further tracking work at multiple sites could assess overlap between colonies and the ecological and conservation importance of these interactions. In particular, it would be valuable to explore the extent to which males and females may be differentially exposed to threats such as fisheries by-catch or contaminants during this vulnerable phase of the annual cycle (Fauchald et al. 2002, Anderson et al. 2011, Van Franeker et al. 2011).

Annual variation in environmental conditions and prey availability are recognised to have profound consequences for breeding phenology (Frederiksen et al. 2004, Wanless et al. 2009), and may similarly affect the timing or duration of moult. For example, experimental studies on passerines suggest that feeding resources during the non-breeding season could influence the timing of pre-alternate moult initiation in wild birds (Danner et al. 2015). We found no evidence of interannual variation in moult initiation in the years we studied, but the 
duration of moult did vary between years (Tables $2 \& 3$ ). However, our estimates of moult duration did vary markedly, with some individuals undergoing moults of up to 120 days (Fig. 2; Supporting Information Table S1). This, together with small sample sizes in some years constrained a more detailed assessment of these patterns, but these results highlight the potential for using individual-based activity data to explore the importance of intrinsic and extrinsic drivers of such variation. Studies of beached Northern Fulmars during winters with unusually high mortality indicate that feather renewal had slowed down or fully arrested in many of these birds, resulting in highly degraded flight feathers and poor down plumage (Van Franeker 2011). Future work could link activity based estimates of moult patterns and flight behaviour with direct measures of feather quality at subsequent capture (e.g. Dawson et al. 2000), or indirect measures of over-winter stress from measures of feather cortisol (e.g. Ramos et al. 2018). Integration of these approaches with long-term deployments of tri-axial accelerometer loggers (Williams et al. 2017) would be particularly valuable for understanding the energetic consequences of observed differences in moult patterns. In contrast to Northern Fulmars, Southern Fulmars Fulmarus glacialoides exhibit extensive overlap between moult and breeding, with a high level of primary moult even during late incubation (Barbraud \& Chastel 1998). These two species are otherwise similar in many aspects of their ecology and biology, and this overlap may result from food availability being very high but restricted to a short Antarctic summer (Barbraud \& Chastel 1998). Others have suggested that the duration of moult may also vary in different environments. For example, Murphy and King (1992) proposed that wintering areas used for moult could influence timing at the species or even population level, with birds experiencing a shorter moult at higher latitudes. Here again, there is potential to use the analyses developed by Gutowsky et al. (2014) and Cherel et al. (2016) to test this hypothesis upon widely distributed species by integrating geolocation and activity data collected from high and low latitude colonies.

In conclusion, these results demonstrate that the breeding performance of Northern Fulmars subsequently influences other life-cycle events such as moult during the nonbreeding season. One important question arising from this is the extent to which this variation may lead to longer-term carry-over effects. In a multi-colony study of carry-over effects in Black-legged Kittiwakes Rissa tridactyla, Bogdanova et al. (2017) detected links between the timing of migration and subsequent breeding events, but annual variations in environmental conditions weakened the strength of these effects. Carry-over effects could arise directly through energetic constraints, or because the renewal of plumage provides a signal of body condition in many species (Lantz \& Karubian 2016), meaning moult could influence breeding performance through mate choice. Further work with additional multi-year data from known 
456

457

458

459

460

461

462

463

464

465

466

467

468

469

470

471

472

473

474

475

476

477

478

479

480

481

482

483

484

485

486

487

488

489

490

491

breeders could explore how the patterns we observed in Northern Fulmars interact with environmental variation, and whether moult phenology influences subsequent breeding attempts as seen in some larger species with more complex biennial moult patterns (Rohwer et al. 2011).

We thank Orkney Islands Council for access to Eynhallow and all the fieldworkers involved in deployment and recovery of the GLS tags and colony monitoring. All ringing work was carried out under permit from the BTO. We are grateful to James Fox of Migrate Technologies for recovering data from GLS loggers which would not download, and Richard Phillips and Janet Silk of BAS for advice on GLS analysis. Lucy Quinn was supported by a NERC Studentship and additional funding to support fieldwork was gratefully received from Talisman Energy (UK) Ltd. Additional support for loggers and analysis was provided through the SEATRACK project, which is funded by the Norwegian Ministry of Climate and Environment, the Norwegian Ministry of Foreign Affairs and the Norwegian Oil and Gas Association.

\section{REFERENCES}

Allard, K. A., M. L. Mallory, K. L. Wilcox, and M. R. Forbes. 2008. Prebasic molt initiation and progress in Northern Fulmars of the High Arctic: do molt and breeding overlap? Polar Biol. 31: $181-188$

Anderson, A. 1962. A count of Fulmars on Hirta, St Kilda in July 1961. Scottish Naturalist. Anderson, O. R. J., C. J. Small, J. P. Croxall, E. K. Dunn, B. J. Sullivan, O. Yates, and A. Black. 2011. Global seabird bycatch in longline fisheries. End. Spec. Res. 14:91-106.

Barbraud, C., and O. Chastel. 1998. Southern Fulmars molt their primary feathers while incubating. Condor 100:563-566.

Bartoń, K. 2016. MuMIn: Multi-Model Inference. Model selection and model averaging based on information criteria. $\mathrm{R}$ package version 1.15.6. http://CRAN.Rproject.org/package=MuMIn

Bates, D., M. Mächler, B. M. Bolker, and S. C. Walker. 2015. Fitting Linear Mixed-Effects Models Using lme4. J. of Stat. Soft. 67:1-48. 
Bogdanova, M. I., A. Butler, S. Wanless, B. Moe, T. Anker-nilssen, M. Frederiksen, T.

493 Boulinier, L. S. Chivers, S. Christensen-Dalsgaard, S. Descamps, M. P. Harris, M. Newell, 494 B. Olsen, R. A. Phillips, D. Shaw, H. Steen, H. Strøm, T. L. Thórarinsson, and F. Daunt. 2017. Multi-colony tracking reveals spatio-temporal variation in carry-over effects between breeding success and winter movements in a pelagic seabird. Mar. Ecol. Prog. Series 578:167-181.

Bretz, F., and P. Westfall. 2008. Simultaneous inference in general parametric models. Biometrical Journal 50:346-363.

Bridge, E. 2006. Influences of morphology and behavior on wing-molt strategies in seabirds. Mar. Ornithol. 34:7-19.

Bridge, E. 2011. Mind The Gaps: What's Missing in Our Understanding of Feather Molt. Condor 113:1-4.

Brown, R. G. B. 1988. The wing-moult of fulmars and shearwaters (Procellariidae) in Canadian Atlantic waters. Canadian Field-Naturalist 102:203-208.

Bugoni, L., L. C. Naves, and R. W. Furness. 2015. Moult of three Tristan da Cunha seabird species sampled at sea. Antarctic Science 27:240-251.

Carrick, R., and M. G. Dunnet. 1954. Breeding of the Fulmar Fulmarus glacialis. Ibis 96:356-370.

Catry, P., M. P. Dias, R. A. Phillips, and J. P. Granadeiro. 2013. Carry-over effects from breeding modulate the annual cycle of a long-distance migrant: an experimental demonstration. Ecology 94:1230-1235.

Cherel, Y., J.-B. Charrassin, and E. Challet. 1994. Energy and protein requirements for molt in the king penguin Aptenodytes patagonicus. The Amer. J. of Physiol. 266:R1182-1188.

Cherel, Y., P. Quillfeldt, K. Delord, and H. Weimerskirch. 2016. Combination of at-sea activity, geolocation and feather stable isotopes documents where and when seabirds molt. Front. in Ecol. and Evol. 4:3. 
528 Cordes, L. S., H. E. Hedworth, D. Cabot, M. Cassidy, and P. M. Thompson. 2015. Parallel declines in survival of adult Northern Fulmars Fulmarus glacialis at colonies in Scotland and Ireland. Ibis 157:631-636.

Coulson, J. C., and J. M. Horobin. 1972. Annual re-occupation of breeding sites by fulmar. 533 Ibis 114:30-42.

Croxall, J. P., J. R. D. Silk, R. A. Phillips, V. Afanasyev, and D. R. Briggs. 2005. Global circumnavigations: tracking year-round ranges of nonbreeding albatrosses. Science 307:249-250.

Croxall, J. P., S. H. M. Butchart, B. E. N. Lascelles, A. J. Stattersfield, B. E. N. Sullivan, A. Symes, and P. Taylor. 2012. Seabird conservation status, threats and priority actions: a 541 global assessment. Bird Conserv. Int. 22:1-34.

Danner, R. M., R. S. Greenberg, J. E. Danner, and J. R. Walters. 2015. Winter food limits 267.

Dawson, A., S. Hinsley, P. Ferns, R. C. Bonser, and L. Eccleston. 2000. Rate of moult affects feather quality: a mechanism linking current reproductive effort to future survival. Proc. R. Soc. Lond. B: Biol. Sciences 267:2093-2098.

Dias, M. P., J. P. Granadeiro, and P. Catry. 2013. Individual variability in the migratory path and stopovers of a long-distance pelagic migrant. An. Behav. 86:359-364. $133: 24-27$. feathers of two Albatross species. Condor 107:835-848. 
560 Edwards, E. W. J., L. R. Quinn, and P. M. Thompson. 2016. State-space modelling of

561 geolocation data reveals sex differences in the use of management areas by breeding

562 Northern Fulmars. J. of App. Ecol. 53:1880-1889.

564 Fauchald, P., K. E. Erikstad, and G. H. Systad. 2002. Seabirds and marine oil incidents: is 565 it possible to predict the spatial distribution of pelagic seabirds? J. of App. Ecol. 39:349566360.

Fayet, A. L., R. Freeman, T. Anker-Nilssen, A. Diamond, K. E. Erikstad, D. Fifield, M. G. Fitzsimmons, E. S. Hansen, M. P. Harris, M. Jessopp, A.-L. Kouwenberg, S. Kress, S. Mowat, C. M. Perrins, A. Petersen, I. K. Petersen, T. K. Reiertsen, G. J. Robertson, P. Shannon, I. A. Sigurðsson, A. Shoji, S. Wanless, and T. Guilford. 2017. Ocean-wide Drivers of Migration Strategies and Their Influence on Population Breeding Performance in a Declining Seabird. Curr. Biol. 27:3871-3878.e3.

Fox, J. 2010. Geolocator manual v8. British Antarctic Survey, Cambridge

Fox, J., and S. Weisberg. 2011. An R Companion to Applied Regression, Second Edition.

Fox, J. 2015. Intiproc geolocation processing software. user reference manual Intiproc v1.03 (January 2015). Migrate Technology Ltd, Cambridge

Frederiksen, M., M. P. Harris, F. Daunt, P. Rothery, and S. Wanless. 2004. Scale-dependent climate signals drive breeding phenology of three seabird species. Glob. Change Biol. 10:1214-1221. Boulinier, J. W. Chardine, O. Chastel, L. S. Chivers, S. Christensen-Dalsgaard, C. ClémentChastel, K. Colhoun, R. Freeman, A. J. Gaston, J. González-Solís, A. Goutte, D. Grémillet, T. Guilford, G. H. Jensen, Y. Krasnov, S. H. Lorentsen, M. L. Mallory, M. Newell, B. Olsen,

591 D. Shaw, H. Steen, H. Strøm, G. H. Systad, T. L. Thórarinsson, and T. Anker-Nilssen. 2012. Multicolony tracking reveals the winter distribution of a pelagic seabird on an ocean basin scale. Div. and Distrib. 18:530-542. 
Furness, R. W. 1988. Influences of Status and Recent Breeding Experience on the Molt

596

597

598

599

600

601

602

603

604

605

606

607

608

609

610

611

612

613

614

615

616

617

618

619

620

621

622

623

624

625

626

627

628

629

Strategy of the Yellow-Nosed Albatross Diomedea chlororhynchos. J. of Zool. 215:719727.

Green, J. A., P. J. Butler, A. J. Woakes, and I. L. Boyd. 2004. Energetics of the moult fast in female macaroni penguins Eudyptes chrysolophus. J. of Avian Biol. 35:153-161.

Guillemette, M., D. Pelletier, J.-M. Grandbois, and P. Butler. 2007. Flightlessness and the energetic cost of wing molt in a large sea duck. Ecology 88:2936-2945.

Gutowsky, S. E., L. F. G. Gutowsky, I. D. Jonsen, M. L. Leonard, M. B. Naughton, M. D. Romano, and S. A. Shaffer. 2014. Daily activity budgets reveal a quasi-flightless stage during non-breeding in Hawaiian albatrosses. Mov. Ecol. 2:23.

Hahn, T. P., J. Swingle, J. C. Wingfield, and M. Ramenofsky. 1992. Adjustments of the prebasic molt schedule in birds. Ornis Scand. 23:314-321.

Hanssen, S. A., G. Gabrielsen, J. Bustnes, V. S. Bråthen, E. Skottene, A. Fenstad, H. Strøm, V. Bakken, R. Phillips and B. Moe. 2016. Migration strategies of common eiders from Svalbard: implications for bilateral conservation management. Polar Biol. 39:2179-2188.

Harris, M. P., S. Wanless, and J-K. Jensen. 2014. When are Atlantic Puffins Fratercula arctica in the North Sea and around the Faroe Islands flightless? Bird Study 61:182-192.

Harris, M. P., S. Wanless, M. Ballesteros, B. Moe, F. Daunt, and K. E. Erikstad. 2015. Geolocators reveal an unsuspected moulting area for Isle of May Common Guillemots Uria aalge. Bird Study 62:267-270.

Hemborg, C., and A. Lundberg. 1998. Costs of overlapping reproduction and moult in passerine birds: An experiment with the pied flycatcher. Behav. Ecol. and Sociobiol. 43:1923.

Hijmans, R. J. 2016. geosphere: Spherical Trigonometry. R package version 1.5-5. https://CRAN.R-project.org/package=geosphere 
630 Keogan, K., F. Daunt, S. Wanless, R. A. Phillips, C. A. Walling, P. Agnew, D. G. Ainley, 631 T. Anker-Nilssen, G. Ballard, R. T. Barrett, K. J. Barton, C. Bech, P. Becker, P.-A. 632 Berglund, L. Bollache, A. L. Bond, S. Bouwhuis, R. W. Bradley, Z. M. Burr, K. 633 Camphuysen, P. Catry, A. Chiaradia, S. Christensen-Dalsgaard, R. Cuthbert, N. Dehnhard, 634 S. Descamps, T. Diamond, G. Divoky, H. Drummond, K. M. Dugger, M. J. Dunn, L. 635 Emmerson, K. E. Erikstad, J. Fort, W. Fraser, M. Genovart, O. Gilg, J. González-Solís, J. 636 P. Granadeiro, D. Grémillet, J. Hansen, S. A. Hanssen, M. Harris, A. Hedd, J. Hinke, J. M. 637 Igual, J. Jahncke, I. Jones, P. J. Kappes, J. Lang, M. Langset, A. Lescroël, S.-H. Lorentsen, 638 P. O. B. Lyver, M. Mallory, B. Moe, W. A. Montevecchi, D. Monticelli, C. Mostello, M. 639 Newell, L. Nicholson, I. Nisbet, O. Olsson, D. Oro, V. Pattison, M. Poisbleau, T. Pyk, F. 640 Quintana, J. A. Ramos, R. Ramos, T. K. Reiertsen, C. Rodríguez, P. Ryan, A. Sanz-Aguilar, 641 N. M. Schmidt, P. Shannon, B. Sittler, C. Southwell, C. Surman, W. S. Svagelj, W. 642 Trivelpiece, P. Warzybok, Y. Watanuki, H. Weimerskirch, P. R. Wilson, A. G. Wood, A. 643 B. Phillimore, and S. Lewis. 2018. Global phenological insensitivity to shifting ocean 644 temperatures among seabirds. Nature Clim. Change 8:313-318.

Kirby, J. S. 1995. Winter population estimates for selected waterfowl species in Britain. Biol. Conserv. 73:189-198.

648

Krüger, L., J. A. Ramos, J. C. Xavier, D. Grémillet, J. González-Solís, Y. Kolbeinsson, T. Militão, J. Navarro, M. V. Petry, R. A. Phillips, I. Ramírez, J. M. Reyes-González, P. G. Ryan, I. A. Sigurðsson, E. V. Sebille, R. M. Wanless, and V. H. Paiva. 2017. Identification of candidate pelagic marine protected areas through a seabird seasonal-, multispecific- and extinction risk-based approach. Animal Conserv. 20:409-424.

654

Lantz, S. M., and J. Karubian. 2016. Male Red-backed Fairywrens appear to enhance a 656 plumage-based signal via adventitious molt. Auk 133:338-346.

657

658 Lascelles, B. G., P. R. Taylor, M. G. R. Miller, M. P. Dias, S. Oppel, L. Torres, A. Hedd, 659 M. Le Corre, R. A. Phillips, S. A. Shaffer, H. Weimerskirch, and C. Small. 2016. Applying 660 global criteria to tracking data to define important areas for marine conservation. Div. and 661 Distrib. 22:422-431. 
663 Lewis, S., D. A. Elston, F. Daunt, B. Cheney, and P. M. Thompson. 2009. Effects of 664 extrinsic and intrinsic factors on breeding success in a long lived seabird. Oikos 118:521 665528.

666

667 Linnebjerg, J. F., N. P. Huffeldt, K. Falk, F. R. Merkel, A. Mosbech, and M. Frederiksen. 668 2014. Inferring seabird activity budgets from leg-mounted time-depth recorders. J. of 669 Ornithol. 155:301-306.

670

671 Macdonald, M. A. 1980. Winter attendance of Fulmars at land in NE Scotland. Ornis Scand. $672 \quad 11: 23-29$.

673

674 Mackley, E. K., R. A. Phillips, J. R. D. Silk, E. D. Wakefield, V. Afanasyev, and R. W. 675 Furness. 2011. At-sea activity patterns of breeding and non-breeding white-chinned petrels 676 Procellaria aequinoctialis from South Georgia. Marine Biol. 158:429-438.

678 Mattern, T., J. F. Masello, U. Ellenberg, and P. Quillfeldt. 2015. Actave.net - a web-based 679 tool for the analysis of seabird activity patterns from saltwater immersion geolocators. 680 Meth. in Ecol. and Evol. 6:859-864.

681

682 Murphy, M. E., and J. R. King. 1992. Energy and nutrient use during molt by White683 Crowned Sparrows Zonotrichia leucophrys gambelii. Ornis Scand. 23:304-313.

684

685 Murphy, M. E. 1996. Energetics and nutrition of molt. Avian Energetics and Nutritional 686 Ecology :158-198

687

688 Owen, E., F. Daunt, C. Moffat, D. A. Elston, S. Wanless, and P. Thompson. 2013. Analysis 689 of fatty acids and fatty alcohols reveals seasonal and sex-specific changes in the diets of 690 seabirds. Marine Biol. 160:987-999.

691

692 Phillips, R. A., J. R. D. Silk, J. P. Croxall, V. Afanasyev, and D. R. Briggs. 2004. Accuracy 693 of geolocation estimates for flying seabirds. Marine Ecol. Prog. Series 266:265-272. 694

695 Prince, P. A., S. Rodwell, M. Jones, and P. Rothery. 1993. Molt in Black-Browed and Gray696 Headed Albatrosses Diomedea melanophris and D. chrysostoma. Ibis 135:121-131. 
698 Quinn, L. R. 2014. Intra- and inter-colony differences in non-breeding strategies in the

699 Northern Fulmar, Fulmarus glacialis. PhD Thesis, University of Aberdeen, 207pp.

Quinn, L. R., A. A. Meharg, J. A. V. Franeker, I. M. Graham, and P. M. Thompson. 2016.

702

703

704

705

706

707

708

709

710

711

712

713

714

715

716

717

718

719

720

721

722

723

724

725

726

727

728

729

730

731

Validating the use of intrinsic markers in body feathers to identify inter-individual differences in non-breeding areas of Northern Fulmars. Marine Biol. 163:1-12.

R Core Team. 2015. R: A language and environment for statistical computing. R Foundation for Statistical Computing, Vienna, Austria. URL http://www.R-project.org/.

Ramos, R., V. Llabrés, L. Monclús, M. López-Béjar, and J. González-Solís. 2018. Costs of breeding are rapidly buffered and do not affect migratory behavior in a long-lived bird species. Ecology 99:2010-2024

Rohwer, S., A. Viggiano, and J. M. Marzluff. 2011. Reciprocal tradeoffs between molt and breeding in albatrosses. Condor 113:61-70.

Slater, C. A. 1990. First Arrival Dates at two Fulmar Fulmarus glacialis colonies in Norfolk. Bird Study 37:1-4.

Swaddle, J. P., and M. S. Witter. 1997. The effects of molt on the flight performance, body mass, and behavior of European starlings (Sturnus vulgaris): an experimental approach. Can. J.1 of Zool. 75:1135-1146.

Thompson, P. M., and J. C. Ollason. 2001. Lagged effects of ocean climate change on fulmar population dynamics. Nature 413:417-420.

Van Franeker, J.A. 2011. Chemicals in marine plastics and potential risks for a seabird like the Northern Fulmar, Fulmarus glacialis. In: Carswell B, McElwee K, Morison S (eds) Technical Proceedings of the Fifth International Marine Debris Conference. NOAA Technical Memorandum 38, Honolulu, Hawaii, pp 415-418

Van Franeker, J. A., C. Blaize, J. Danielsen, K. Fairclough, J. Gollan, N. Guse, P. L. Hansen, M. Heubeck, J. K. Jensen, G. Le Guillou, B. Olsen, K. O. Olsen, J. Pedersen, E. 
732 W. M. Stienen, and D. M. Turner. 2011. Monitoring plastic ingestion by the Northern

733 Fulmar Fulmarus glacialis in the North Sea. Env. Pollution 159:2609-2615.

734

735 Wanless, S., M. Frederiksen, J. Walton, and M. Harris. 2009. Long-term changes in

736 breeding phenology at two seabird colonies in the western North Sea. Ibis 151:274-285.

738 Williams, H. J., M. D. Holton, E. L. C. Shepard, N. Largey, B. Norman, P. G. Ryan, O.

739 Duriez, M. Scantlebury, F. Quintana, E. A. Magowan, N. J. Marks, A. N. Alagaili, N. C.

740 Bennett, and R. P. Wilson. 2017. Identification of animal movement patterns using tri-axial magnetometry. Mov. Ecol. 5:6.

\section{SUPPORTING INFORMATION}

Additional Supporting Information may be found in the online version of this article:

Appendix S1. R code to calculate daily activity summaries

Figure S1. Example of fitted GAM model, with 95\% CI.

Figure S2. Location of the moulting Northern Fulmars breeding at Eynhallow,

749 including data from during the equinox (in contrast to Figure 4 in the main paper).

Table S1. Summary data on the moult characteristic of all individuals

Table S2. Detailed sample sizes per cycle year. 
TABLES \& FIGURES

754

755

756

757

758

759

\begin{tabular}{|c|c|c|c|c|}
\hline $\begin{array}{l}\text { Response } \\
\text { variable }\end{array}$ & $\begin{array}{c}\text { Significant explanatory } \\
\text { variable(s) }\end{array}$ & $P$-value & Wald Chisq & $\begin{array}{c}\text { Random effect } \\
\text { variance }\end{array}$ \\
\hline Start date & Breeding status & $<0.0001$ & 248.50 & 3.30 \\
\hline \multirow{2}{*}{ Median date } & Breeding status & $<0.0001$ & 204.53 & \multirow{2}{*}{5,06} \\
\hline & Sex & 0.055 & 3.67 & \\
\hline Duration & Cycle year & 0.003 & 17.81 & 23.56 \\
\hline
\end{tabular}

760

761 Table 1. Results of the significance of different explanatory variables for each response variable

762 used with the linear mixed model including bird number as a random effect.

763 


\begin{tabular}{|c|c|c|c|c|c|c|}
\hline & $\sim \operatorname{sex}$ & + breeding status & + cycle year & + sex $:$ breeding status & $\triangle \mathrm{AICc}$ & wAICc \\
\hline \multirow[t]{5}{*}{ Start date } & & $* * *$ & & & 11.524 & 0 \\
\hline & & $* * *$ & & & 5.159 & 0.06 \\
\hline & & $* * *$ & & & 4.134 & 0.1 \\
\hline & & $* * *$ & & & 0 & 0.83 \\
\hline & & & & & 135.142 & 0 \\
\hline \multirow[t]{5}{*}{ Median date } & & $* * *$ & . & & 9.128 & 0.01 \\
\hline & $*$ & $* * *$ & - & & 2.168 & 0.18 \\
\hline & . & $* * *$ & & & 0 & 0.54 \\
\hline & & $* * *$ & & & 1.404 & 0.27 \\
\hline & & & & & 117.889 & 0 \\
\hline \multirow[t]{5}{*}{ Duration } & & & $*$ & & 9.956 & 0 \\
\hline & & & $*$ & & 5.52 & 0.03 \\
\hline & & & $* *$ & & 0.028 & 0.47 \\
\hline & & & $* *$ & & 0 & 0.47 \\
\hline & & & & & 5.544 & 0.03 \\
\hline
\end{tabular}

766 Table 2. Model selection based on AICc, for the three response variables (start date of moult, 767 median date of moult and duration of moult), using linear mixed models including bird 768 number as a random effect. Explanatory variables used in each model are highlighted in grey.

769 Significance of each explanatory variables used is represented as follows: $\cdot(P<0.1)$; * $(P<$ $7700.05) ; * *(P<0.01) ; * * *(P<0.001)$. The best-fitting model is represented between the 771 dotted lines. 


\begin{tabular}{|c|c|c|c|c|c|}
\hline Breeding status & $\mathbf{N}$ & Start date & Median date & End date & Duration \\
\hline Not recorded breeding & 13 & 26 July $( \pm 2.8)^{\mathrm{a}}$ & 2 September $( \pm 2.1)^{\mathrm{a}}$ & 9 October $( \pm 3.1)$ & $75.3( \pm 4.2)^{\mathrm{a}}$ \\
\hline Failed on an egg & 19 & 27 July $( \pm 2.3)^{\text {a }}$ & 1 September $( \pm 2.2)^{\mathrm{a}}$ & 6 October $( \pm 2.9)$ & $70.4( \pm 2.8)^{\mathrm{a}}$ \\
\hline Failed on a chick & 33 & 13 August $( \pm 2.3)^{\mathrm{b}}$ & 16 September $( \pm 2.1)^{\mathrm{b}}$ & 20 October $( \pm 2.5)$ & $68.3( \pm 2.2)^{\mathrm{a}}$ \\
\hline Successfully fledged & 74 & 27 August $( \pm 0.9)^{\mathrm{c}}$ & 30 September $( \pm 1.1)^{\mathrm{c}}$ & 2 November $( \pm 1.9)$ & $66.7( \pm 1.9)^{\mathrm{a}}$ \\
\hline \multicolumn{6}{|l|}{ Cycle year } \\
\hline $2008 / 2009$ & 15 & 20 August $( \pm 2.5)^{\mathrm{a}}$ & 28 September $( \pm 2.7)^{\mathrm{a}}$ & 6 November $( \pm 3.6)$ & $78.5( \pm 3.1)^{\mathrm{a}}$ \\
\hline $2009 / 2010$ & 24 & 18 August $( \pm 2.5)^{\mathrm{a}}$ & 19 September $( \pm 2.3)^{\mathrm{a}}$ & 20 October $( \pm 2.7)$ & $63.5( \pm 2.7)^{\mathrm{b}}$ \\
\hline $2010 / 2011$ & 35 & 22 August $( \pm 2.1)^{a}$ & 23 September $( \pm 2.4)^{\mathrm{a}}$ & 25 October $( \pm 3.1)$ & $64.6( \pm 2.4)^{\mathrm{b}}$ \\
\hline $2011 / 2012$ & 14 & 28 July $( \pm 3.4)^{\mathrm{a}}$ & 3 September $( \pm 2.8)^{\mathrm{a}}$ & 11 October $( \pm 3.5)$ & $75.6( \pm 3.9)^{a, b}$ \\
\hline $2014 / 2015$ & 28 & 22 August $( \pm 3.4)^{a}$ & 25 September $( \pm 3.2)^{\mathrm{a}}$ & 28 October $( \pm 3.8)$ & $67.0( \pm 3.2)^{\mathrm{a}, \mathrm{b}}$ \\
\hline $2015 / 2016$ & 23 & 11 August $( \pm 3.6)^{a}$ & 15 September $( \pm 3.4)^{\mathrm{a}}$ & 20 October $( \pm 3.9)$ & $70.1( \pm 3.3)^{\mathrm{a}, \mathrm{b}}$ \\
\hline \multicolumn{6}{|l|}{ Sex } \\
\hline Males & 77 & 17 August $( \pm 1.8)^{a}$ & 21 September $( \pm 1.8)^{\mathrm{a}}$ & 26 October $( \pm 2.1)$ & $69.6( \pm 1.6)^{\mathrm{a}}$ \\
\hline Females & 62 & 16 August $( \pm 2.1)^{\mathrm{a}}$ & 18 September $( \pm 1.9)^{\mathrm{a}}$ & 22 October $( \pm 2.2)$ & $66.9( \pm 2.1)^{\mathrm{a}}$ \\
\hline
\end{tabular}

774

775 Table 3. Timing of the moult by biotic and abiotic factors. Values are mean dates $( \pm \mathrm{SE})$.

776 Results from the post hoc Tukey tests are presented (values not sharing the same superscript 777 letter are significantly different at $P<0.05)$. As we chose not to use end date as a response 778 variable in our model because of its high correlation to start date and duration, no post hoc 779 results are available. 
788 Figure 1. Variation in the mean daily percentage of time spent on water $( \pm$ SD) for 139 annual 789 cycles from 82 individual Northern Fulmars tracked between 2007 and 2016 (left axis). For 790 comparison, the dashed line represents the cumulative proportion of birds that had completed 791 their primary moult in the dataset from beached and by-caught North Sea Northern Fulmars 792 (from Quinn et al. 2016, right axis).

793

794

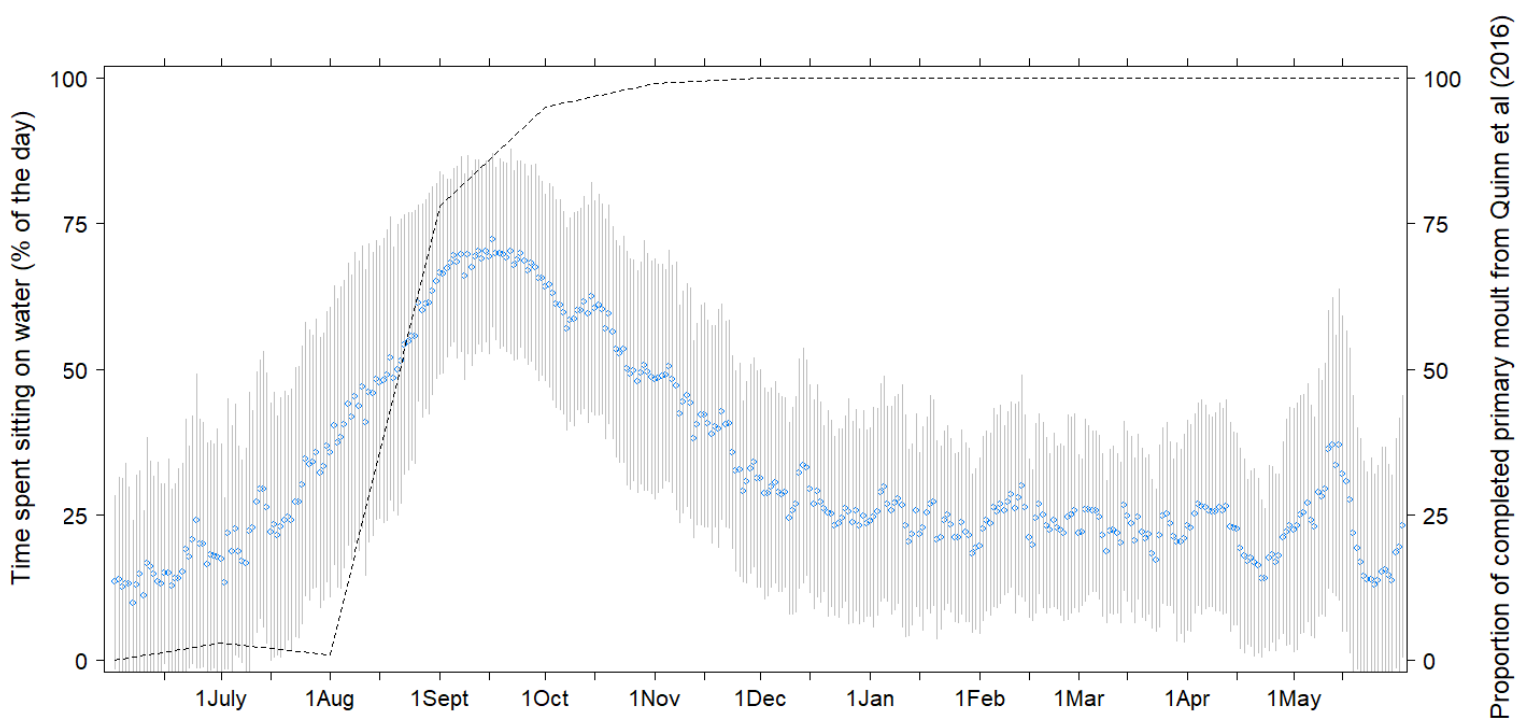


798 Figure 2. Variability in the timing of the moult. Distribution of the characteristics of the moult 799 extracted from the activity data using GAM. The boxes depict interquartile range, with median 800 as a bold line. Whiskers indicate variability outside the upper and lower quartiles. Outliers are 801 plotted as circles. (A: Start date; B: Median date; C: End date; D: Duration). 802 803

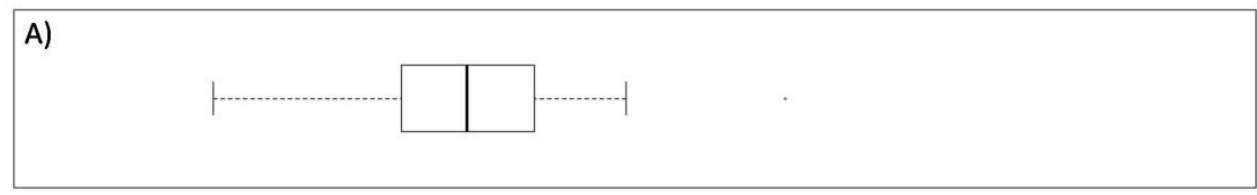

B)

804
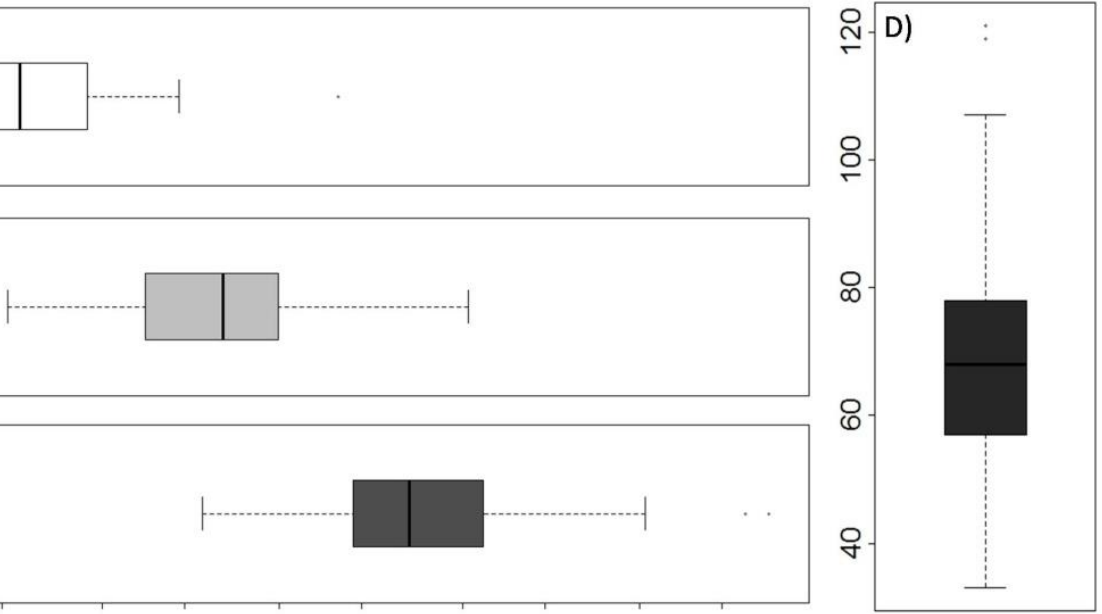

805

806

807

808 
809 Figure 3. Differences in the starting date of the moult explained by breeding status. The boxes 810 depict interquartile range, with median as a bold line. Whiskers indicate variability outside the 811 upper and lower quartiles. Outliers are plotted as circles.

812

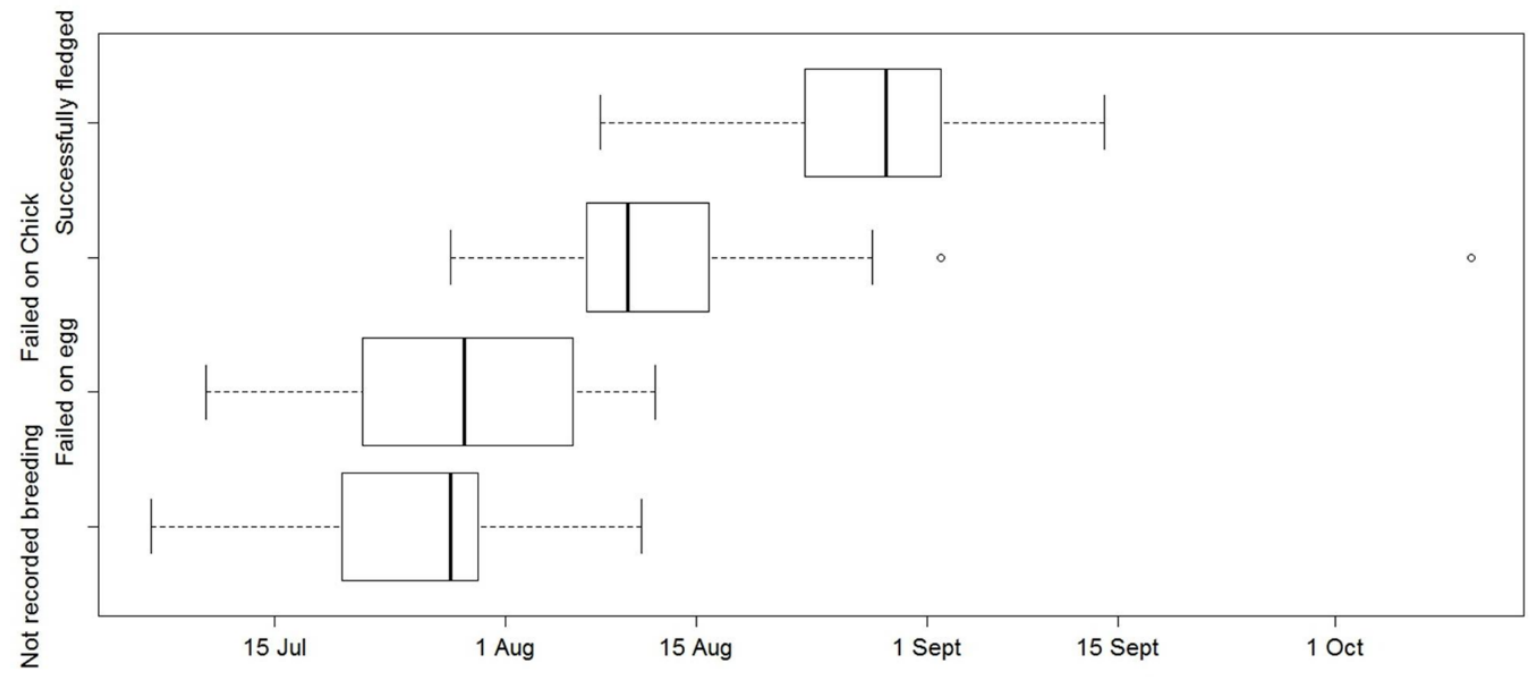

813

814

815

816

817 
818 Figure 4. Location of the moulting Northern Fulmars breeding at Eynhallow (colony

819 represented by the yellow star). Points represent the geographic mean moulting location

820 calculated from the locations between the start and end dates of each individual's moult,

821 excluding locations from within the autumn equinox. Males are represented by blue points

822 and females by red points $(n=135$, as mean locations were not calculated for the four

823 individuals where locations could not be determined for $>75 \%$ of days during the moult; see

824 Table S1).

825

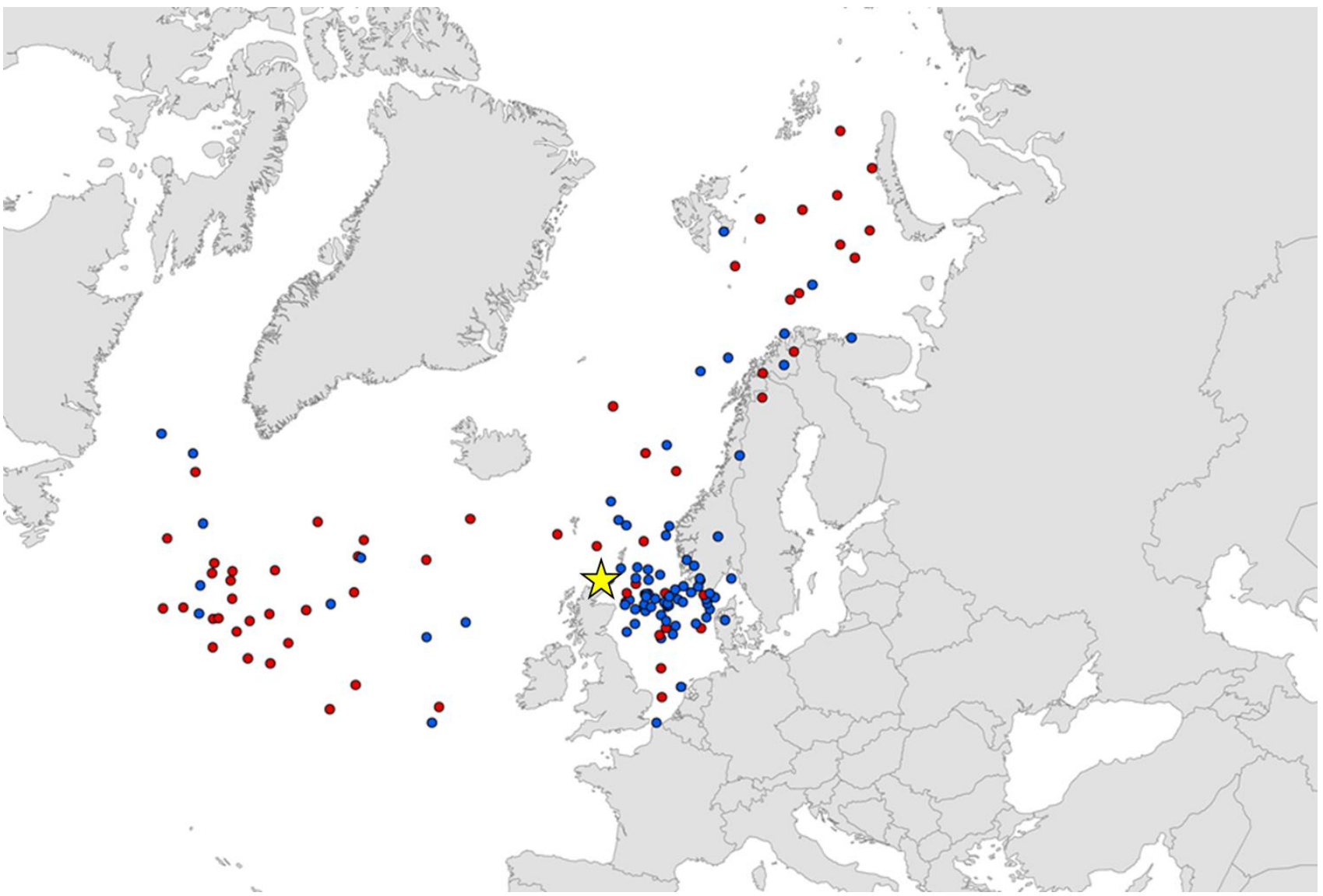


830 Figure 5. Boxplot showing the sex difference in the distance between an individual's 831 geographic mid-point during the moult and the breeding colony. The boxes depict interquartile 832 range, with median as a bold line. Whiskers indicate variability outside the upper and lower 833 quartiles. Outliers are plotted as circles.

834

835

836

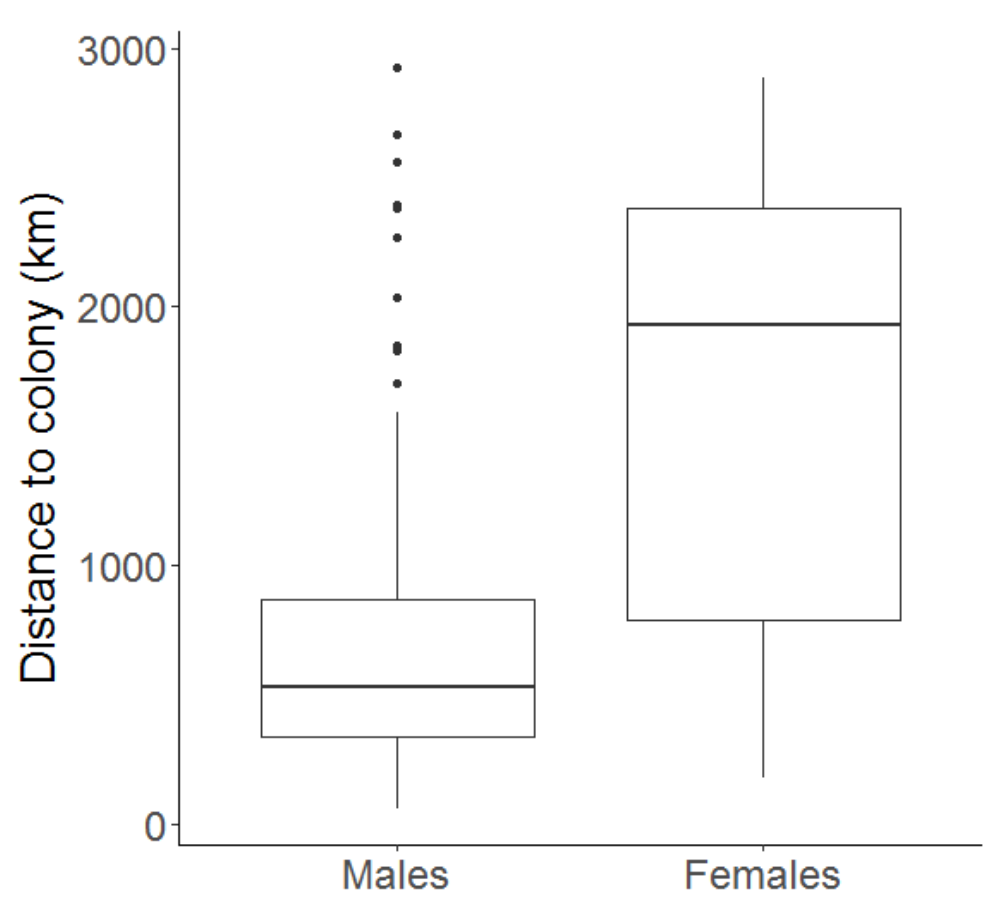

